\title{
ATR-FTIR and Nanoindentation Measurements of PMDA-ODA Polyimide Film under Different Curing Temperature
}

\author{
Shih-Chin Lee ${ }^{1}$, Fong-Cheng Tai ${ }^{1, *}$, Che-Hung Wei ${ }^{2}$ and Jui-I Yu ${ }^{3}$ \\ ${ }^{1}$ Department of Materials Science and Engineering, National Cheng-Kung University, Tainan 701, Taiwan \\ ${ }^{2}$ Department of Mechanical Engineering, TATUNG University, Taipei 104, Taiwan \\ ${ }^{3}$ Institute of Materials Science and Engineering, National Sun Yat-sen University, Kaohsiung 804, Taiwan
}

\begin{abstract}
ATR-FTIR apparatus is used to measure the curing rate of PMDA-ODA polyimide film in order to avoid sinusoidal interference fringe. From the corrected height method, the curing rate is found to have positive correlative trend with the curing temperature. It was shown that the curing rate under $300^{\circ} \mathrm{C}$ is $92.1 \%$ than that under $400^{\circ} \mathrm{C}$ for one hour. The curing degree related to the mechanical properties was further demonstrated by nanoindentation. The results show that the higher the curing rate the higher the nano-hardness and nano-modulus due to the thermal imidization of polyimide characteristic. The nano-hardness ratio of curing degree at $300{ }^{\circ} \mathrm{C}$ over curing degree at $400{ }^{\circ} \mathrm{C}$ is 0.89 , while the nano-modulus of which is 0.95. [doi:10.2320/matertrans.MER2007045]
\end{abstract}

(Received February 20, 2007; Accepted April 10, 2007; Published May 25, 2007)

Keywords: Curing temperature, ATR-FTIR (Attenuated total reflectance-Fourier transform infrared spectrometer), micro-hardness, nanoelastic modulus, nano-hardness

\section{Introduction}

Since the early $1970 \mathrm{~s}$ and the late $1980 \mathrm{~s}$, polyimide film has been used as intermetal dielectric (IMD) or passivation layer in IC device due to its many outstanding properties, like low dielectric constant $(3.0 \sim 4.0)$, high thermal resistance and high chemical resistance. However, the polyimide also has some drawbacks, such as anisotropolyimidec index (different CTE in vertical and parallel to film plane), significant water absorption (increasing the film's dielectric constant). ${ }^{1-3)}$ Some reports have shown the characteristics of the some polyimide films are strongly affected by the curing rates. For examples, both Zelmat and Muruganand used biphenyltetracarboxilic acid dianhydride-pphenylene diamine (BPDA-PPD) polyimide to discuss the correlation between different curing temperature $\left(250^{\circ} \mathrm{C}\right.$ max.) and electrical properties, like permittivity, dielectric loss, leakage current and electric breakdown field strength. ${ }^{4,5)}$ Lee describes the correlation between different curing temperature $\left(350{ }^{\circ} \mathrm{C}\right.$ max.) and electric breakdown field strength by using pyromellitic dianhydride-diaminodiphenyl ether (PMDADDE) polyimide. ${ }^{6}$ Nomura evaluated both heating temperature $\left(350{ }^{\circ} \mathrm{C}\right.$ max.) and heating effects on the curing rate of Biphenyltetracarboxylic dianhydride-pphenylenediamine (BPDA-PDA) polyimide. ${ }^{7)}$ Karamancheva changed the component ratio of pyromellitic dianhydride oxydianiline (PMDA-ODA) polyimide and describe the curing temperature effect on curing rate $\left(350{ }^{\circ} \mathrm{C}\right.$ max. $){ }^{8)}$ Lee investigated the curing temperature $\left(350^{\circ} \mathrm{C}\right.$ max. $)$ effect on de-polymerization of fluorinated polyimide film. ${ }^{9)}$ Amagai discussed the surface morphology effect on mechanical properties (elongation, fracture toughness and density) under different curing temperature $\left(390{ }^{\circ} \mathrm{C}\right.$ max. $){ }^{10)}$ Nishino investigated the residual stress of PMDA-ODA polyimide film under different curing step $\left(400^{\circ} \mathrm{C}\right.$ max. $){ }^{11)}$ Jou also mentioned the residual stress of PMDA-ODA polyimide film under different curing

*Corresponding author, E-mail: fc.tai@msa.hinet.net ramp rate $\left(350{ }^{\circ} \mathrm{C}\right.$ max. $) .{ }^{12)}$ In the case of vapor deposition polymerization method for thin film consideration, the curing temperature of PMDA-ODA polyimide is $400^{\circ} \mathrm{C}$ at Ukishima's report. ${ }^{13)}$ In evaluation of curing degree, Fourier transform infrared spectrometer (FTIR) is a powerful and feasible apparatus to verify the chemical bonding of polymer material. In general, the FTIR consists of three measuring modes, including simple reflectance mode, attenuated total reflectance (ATR) mode and transmission mode, these FTIR modes has been used to measure the curing rate of polyimide film under different curing treatment. ${ }^{14)}$ In terms of polyimide type, the most widely used type is PMDA-ODA polyimide. To our knowledge, there is no study about the general mechanical properties of polyimide film cured under different curing temperature. The purpose of this study is to find out how the mechanical properties such as microhardness, nano-hardness and elastic modulus affected by different curing rate on PMDA-ODA polyimide film.

\section{Experimental Procedure}

PMDA-ODA type of polyimide precursor consists of two major components: PMDA resin and oxydianiline. The PMDA resin (Pyro-mellitic dianhydride: $\mathrm{C}_{10} \mathrm{H}_{2} \mathrm{O}_{6}$ ) contains four $\mathrm{C}=\mathrm{O}$ bonds, two $\mathrm{N}$ atoms, one benzene ring and ODA resin. Oxydianiline $\left(\mathrm{C}_{12} \mathrm{H}_{12} \mathrm{~N}_{2} \mathrm{O}\right)$ contains two benzene ring, one $\mathrm{O}$ atom and NMP solvent (N-methyl-2-pyrrolidone). The PMDA-ODA type of polyimide is fabricated by spin-coating the liquid polyimide precursor (HD Microsystems) on a 6 in bare silicon wafer and heated on a hotplate at $100{ }^{\circ} \mathrm{C}$ for $5 \mathrm{~min}$. After that, soft polyimide was converted to hard polyimide film by curing treatment for one hour curing time. The curing temperature is $300^{\circ} \mathrm{C}, 350{ }^{\circ} \mathrm{C}$ and $400^{\circ} \mathrm{C}$, respectively. The $\mathrm{N}_{2}$ oven is used to cure the polyimide under $\mathrm{N}_{2}$ purging gas with controlled oxygen content less than $100 \mathrm{ppm}$ to avoid oxidation. The details about the transformation from initial polyamic acid (PAA) liquid precursor with open-ring state to final solid polyimide film 


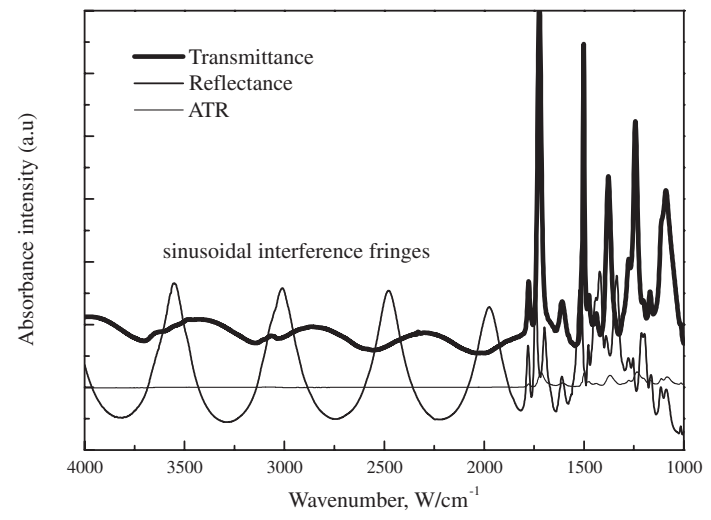

Fig. 1 The three measurement modes of FTIR on polyimide film.

with close imide ring can be found elsewhere. ${ }^{11)}$ In comparison to the Nishino's work for two-step and stepwise curing profile, this study adopts the simple one-step curing profile where the average ramp up rate is $2.0^{\circ} \mathrm{C} / \mathrm{min}$ and the average ramp down rate is $4.0^{\circ} \mathrm{C} / \mathrm{min}$. The finally curing thickness is $6 \mu \mathrm{m}$. FTIR tool (Perkin-Elmer Spectrum 2000) is used to measure the film spectrum and the diameter of ATR probe is $100 \mu \mathrm{m}$. The scan resolution is $4 \mathrm{~cm}^{-1}$ and scan number is 16 . The general definition of curing rate (thermal imidization) means the percentage of polyimide precursor conversion to polyimide, the calculation method for area intensity is listed as follows: ${ }^{11,15-17)}$

\section{Relative curing rate}

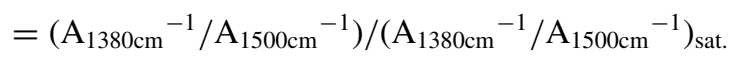

where the $A_{1380 \mathrm{~cm}}{ }^{-1}$ represents the absorption reference imide peak at $1380 \mathrm{~cm}^{-1}$ band due to $\mathrm{C}-\mathrm{N}$ stretching vibration, and the other reference peak $\mathrm{A}_{1500 \mathrm{~cm}}{ }^{-1}$ represents the absorption at $1500 \mathrm{~cm}^{-1}$ band of monomer backbone due to $\mathrm{C}-\mathrm{C}$ stretching vibration. The micro-hardness tester (FUTURE-TECH, digital tester FM, the loading ranges from $10 \mathrm{mN}$ to $10,000 \mathrm{mN}$, the general loading time is 15 seconds) is used to estimate the micro-hardness of polyimide film. In addition to the analysis application on hard and thin film, nanoindentation also could be used to analyze the mechanical characteristics of soft polymer film. The ultra-hardness tester (MTS nano indent XP, the loading increases slowly from zero to $8 \mathrm{mN}$, and the relative loading depth is from zero to $1,000 \mathrm{~nm}$ ) is used to conduct the nano-hardness of polyimide film. The nano-hardness and nano-elastic modulus of soft film on hard substrate can be determined from the continuous stiffness measurement (CSM) technique of dynamic indentation test, the detailed description of simplified hardness and elastic modulus equation, ${ }^{18)}$ and the complex hardness and elastic modulus equation also can be seen elsewhere. ${ }^{19-23)}$

\section{Results and Discussion}

The color transformation of different states in polyimide film is closely related to the surface's micro-structural changes. The color of as-cured polyimide is light brown, brown and dark brown for $300^{\circ} \mathrm{C}, 350^{\circ} \mathrm{C}$ and $400^{\circ} \mathrm{C}$, respectively by optical microscope inspection. Figure 1 shows that the polyimide spectrum curves detected by three

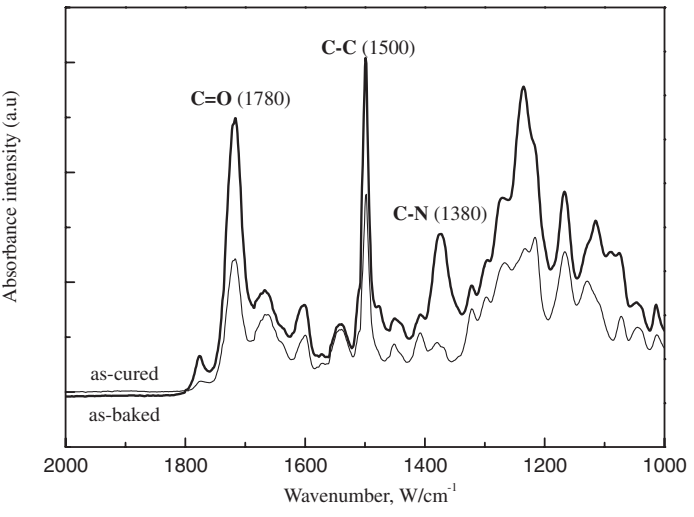

Fig. 2 The ATR-FTIR spectra of curing polyimide films as a function of curing temperature.

FTIR measuring modes, including simple reflectance mode, attenuated total reflectance (ATR) mode and transmission mode. The order of absorption intensity is transmission mode $>$ simple reflectance mode $>$ ATR mode. From this observation, there is interference fringe resulted from polyimide film thickness variance at high frequency band $\left(4000 \sim 1800 \mathrm{~cm}^{-1}\right)$ for transmission and simple reflectance mode. In addition, there is multi-peak which resulted from overlapping polyimide phenomenon at major frequency band $\left(1800 \sim 1000 \mathrm{~cm}^{-1}\right)$. In view of these disadvantages, the ATR mode is the right method to measure the polyimide film spectrum. Figure 2 shows the ATR-FTIR spectra of polyimide films as a function of curing temperature where the $1500 \mathrm{~cm}^{-1}$ peak from C-C stretching vibration of ODA monomer backbone is used as the peak reference characteristic of curing rate. The other pronounced peak is $1380 \mathrm{~cm}^{-1}$ peak which is due to $\mathrm{C}-\mathrm{N}$ stretching vibration of imide ring. The peaks of $1720 \mathrm{~cm}^{-1}$ and $1780 \mathrm{~cm}^{-1}$ also belong to $\mathrm{C}-\mathrm{N}$ stretching vibration of imide ring, but here only the $1380 \mathrm{~cm}^{-1}$ peak is used as the imide peak for curing rate. ${ }^{6,11)}$ The curing rate can be estimated either by corrected height or by corrected area type after the spectrum curve has been adjusted by automatic baseline treatment. Figure 3 shows the curing rate measured by corrected area and corrected height as a function of curing temperature. The corrected height method shows a positive trend. The possible reason might be the overlapping polyimide effect is more pronounced in corrected area method which is in agreement with the report of Karamancheva et al. ${ }^{8)}$ The curing rate measured by ATRFTIR and calculated by corrected height model for polyimide film at $300^{\circ} \mathrm{C}, 350{ }^{\circ} \mathrm{C}$ and $400{ }^{\circ} \mathrm{C}$ is $92.1 \%, 94.7 \%$ and $100 \%$, respectively. But the curing rate under corrected area model are $142.0 \%, 147.1 \%$ and $100 \%$, respectively. Figure 4 shows the surface micro-hardness of polyimide film as a function of curing temperature under the load $50 \mathrm{mN}$. The average micro-hardness for $300^{\circ} \mathrm{C}, 350^{\circ} \mathrm{C}$ and $400^{\circ} \mathrm{C}$ is $0.372 \mathrm{GPa}$, $0.412 \mathrm{GPa}$ and $0.589 \mathrm{GPa}$, respectively. The overall trend is the higher curing temperature the higher micro-hardness. The polyimide film could exhibit de-bonding behavior until the load reaches $3000 \mathrm{mN}$. $^{24}$ )

Figure 5 shows loading part of loading-depth curves of polyimide film as a function of probed depth under different curing temperature. When the indentation load is high 


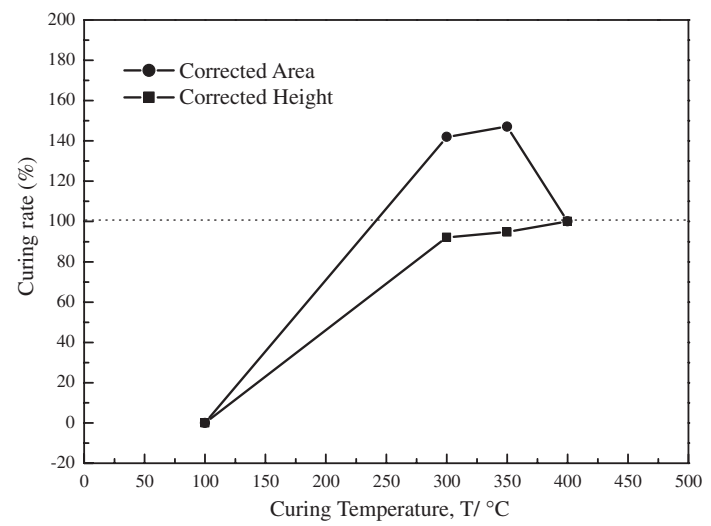

Fig. 3 The curing degree measured by corrected area and corrected height as a function of curing temperature.

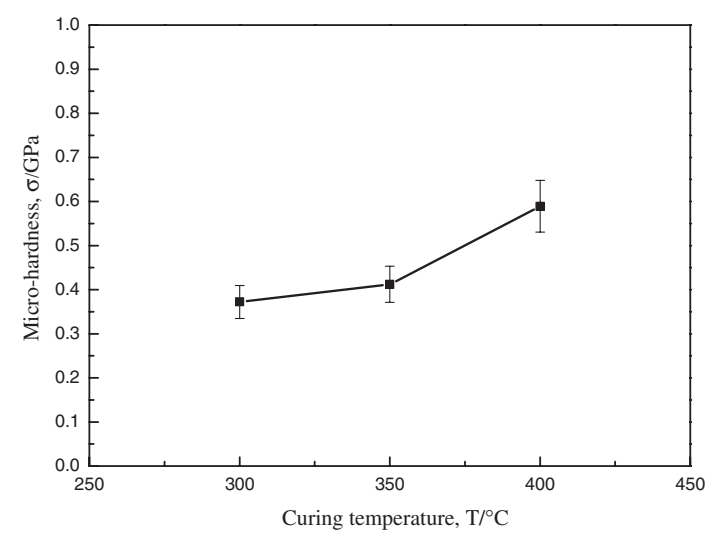

Fig. 4 The micro-hardness of polyimide film as a function of curing temperature.

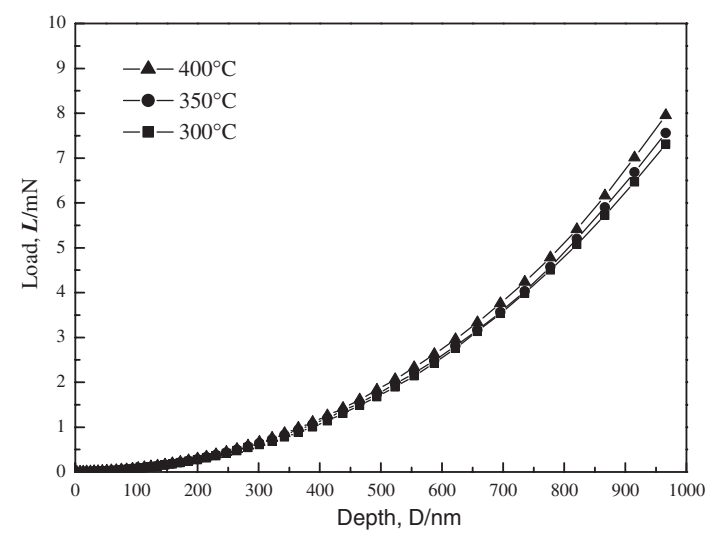

Fig. 5 The load-depth curves of polyimide film as a function of probed depth under different curing temperature.

enough $(>2 \mathrm{mN})$, the loading-depth curve is easier to separate for viewing. The loading curves of polyimide film exhibit continuous and smooth line-shape which suggests there is no de-bonding or cracking occurred during nanoindentation test. ${ }^{25}$ ) Figure 6 shows the nano-hardness of polyimide film as a function of probed depth under different curing temperature. According to the Lugscheider assumption on absorption and oxidation layer of metal surface, ${ }^{26)}$ it is reasonable to postulate that there is a thin inhomogeneous

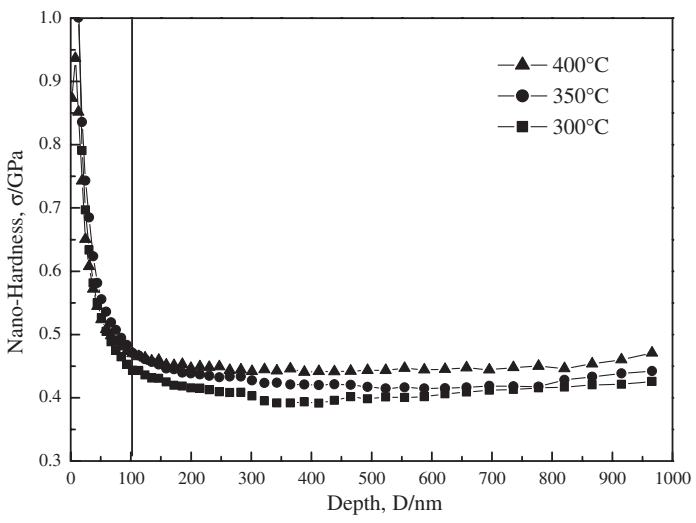

Fig. 6 The nano-hardness of polyimide film as a function of probed depth under different curing temperature.

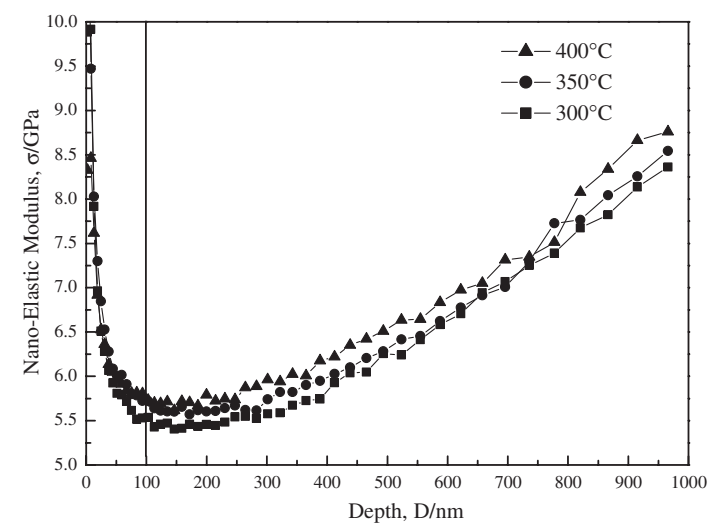

Fig. 7 The nano-elastic modulus of polyimide film as a function of probed depth under different curing temperature.

layer (up to $100 \mathrm{~nm}$ ) on top of the polyimide. ${ }^{27)}$ For probed depth from $100 \mathrm{~nm}$ to $1000 \mathrm{~nm}$, the average nano-hardness for $300^{\circ} \mathrm{C}, 350{ }^{\circ} \mathrm{C}$ and $400^{\circ} \mathrm{C}$ is $0.40 \mathrm{GPa}, 0.43 \mathrm{GPa}$ and $0.45 \mathrm{GPa}$, respectively, the obvious trend is the higher the curing temperature, the higher the nano-hardness due to thermal imidization of polyimide film. From the curve of the nano-hardness versus probe depth, the nano-hardness is near unchanged from $100 \mathrm{~nm}$ to $1000 \mathrm{~nm}$ for each curing temperature. This nano-hardness test result is in agreement with the Shen's research on BD low k film, ${ }^{18)}$ Shen's study on post annealed treatment of PA6 polymer ${ }^{19}$ ) and Lee's report on PMDA-ODA-PDA co-polyimide. ${ }^{23)}$ Figure 7 shows the nano-elastic modulus of polyimide film as a function of probed depth under different curing temperature, from probed depth from $100 \mathrm{~nm}$ to $1000 \mathrm{~nm}$, the average nanomodulus for $300^{\circ} \mathrm{C}, 350^{\circ} \mathrm{C}$ and $400^{\circ} \mathrm{C}$ is $5.58 \mathrm{GPa}, 5.73 \mathrm{GPa}$ and $5.90 \mathrm{GPa}$, respectively. The trend is that the higher curing temperature, the higher nano-elastic modulus. The curve of the nano-elastic modulus versus probe depth means that the nano-elastic modulus is variable from $100 \mathrm{~nm}$ to $1000 \mathrm{~nm}$ for each curing temperature. The increasing trend exhibits that the larger the indentation depth, the higher elastic modulus for each curing temperature due to thermal imidization of polyimide film, and this experimental finding about variable nano-elastic modulus is also consistent with previous reports due to the nano-elastic modulus is much more substrate- 
sensitive than hardness measurement during dynamic nanoindentation test. $18,27,28)$

\section{Conclusion}

From this study, the curing rate of PMDA-ODA polyimide film could be obtained by ATR-FTIR where the data is further used for automatic baseline treatment and corrected height model. The curing rate at $300^{\circ} \mathrm{C}$ could reach $92.1 \%$ of that at $400{ }^{\circ} \mathrm{C}$. Two major mechanical properties, i.e. nanohardness and nano-elastic modulus obtained by nano-indentation test is used to demonstrate how the curing degree affects the properties of polyimide. The nano-hardness of $300{ }^{\circ} \mathrm{C}$ curing degree polyimide is $88.9 \%$ and the elastic modulus is $94.6 \%$ of $400{ }^{\circ} \mathrm{C}$ curing degree polyimide. It has been proved that the curing degree of PMDA-ODA polyimide has certain effect on the mechanical property and due to the nano-elastic modulus is much more substrate-sensitive than hardness measurement during dynamic nanoindentation test.

\section{REFERENCES}

1) G. Maier: Progress in polymer science 26 (2001) 3-65.

2) P. Garrou: IEEE TRANSACTIONS ON ADVANCED PACKAGING 23 (2000) 198-205.

3) J. O. Simpson and A. K. St. Clair: Thin Solid Films 308-309 (1997) 480-485.

4) S. Zelmat, M. L. Locatelli, T. Lebey and S. Diaham: Microelectronic Engineering 83 (2006) 51-54.

5) S. Muruganand, S. K. Narayandass, D. Mangalaraj and T.M. Vijayan: Polymer International 50 (2001) 1089-1094.

6) B. J. Lee, H. G. Kim and D. C. Lee: Surface and Coatings Technology 150 (2002) 182-187.
7) H. Nomura and M. Asano: Jpn. J. Appl. Phys 35 (1996) 5825-5830.

8) I. Karamancheva, V. Stefov, B. Soptrajanov, G. Danev, E. Spasova and J.Assa: Vibrational Spectroscopy 19 (1999) 369-374.

9) Y. K. Lee and S. P. Murarha: JOURNAL OF MATERIALS SCIENCE 33 (1998) 5423-5426.

10) M. Amagai: Microelectronic Reliability 40 (2000) 2077-2086.

11) T. Nishino, M. Kotera, N. Inayoshi, N. Miki and K. Nakamae: Polymer 41 (2000) 6913-6918.

12) J. H. Jou, C. P. Lin and W. H Sheu: J Polym Sci Part B: Polym Phys 33 (1995) 1803-1811.

13) S. Ukishima, M. Iijima, M. Sato, Y. Takahashi and E. Fukada: Thin Solid Films 308-309 (1997) 475-479.

14) J. V. Gulmine, P. R. Janissek, H. M. Heise and L. Akcelrud: Polymer Testing 21 (2002) 557-563.

15) H. T. Kim and J. K. Park: Jpn. J. Appl. Phys. 38 (1999) 201-208.

16) Y.-Kun Xu, M.-Sheng Zhan and K. Wang: J. Polym. Sci. Part B: Polym. Phys. 42 (2004) 2490-2501.

17) Y.-Hua Lu and M.-Sheng Zhan: J. Polym. Sci. Part B: Polym. Phys. 43 (2005) 3621-3627.

18) L. Shen, K. Zeng, Y. Wang, B. Narayanan and R. Kumar: Microelectronic Engineering 70 (2003) 115-124.

19) L. Shen, I. Yee Phang and T. Liu: Polymer Testing 25 (2006) 249-253.

20) H. N. Dhakal, Z. Y. Zhang and M. O. W Richardson: Polymer Testing 25 (2006) 846-852.

21) H.-C. Liou and J. Pretzer: Thin Solid Films 335 (1998) 186-191.

22) C. Lee, J. Kwon, S. Park, S. Sundar, B. Min and H. Han: J. Polym. Sci. Part B: Polym. Phys. 42 (2004) 861-870.

23) C. Lee, N. Padmanabha Iyer and H. Han: J. Polym. Sci. Part B: Polym. Phys. 42 (2004) 2202-2214.

24) S. R. Boddapati, Hong Ma, R. K. Bordia and Alex K. Y. Jen: J. Mater. Res. 21 (2006) 1759-1769.

25) D. Beegan, S. Chowdhury and M. T. Laugier: Thin Solid Films 466 (2006) 167-174.

26) E. Lugscheider, K. Bobzin and M. Moller: Thin Solid Films 355-356 (1999) 367-373.

27) http://www.mtsnano.com, Application note of dynamic indentation.

28) M. herrmann, N. Schwarzer, F. Richter, S. Fruhauf and S. E. Schulz: Surface and Coatings Technology 201 (2006) 4305-4310. 